\title{
A clinical study regarding the improvement of symptoms and the time efficacy of treatments performed in Băile Tușnad balneoclimatic resort
}

\author{
Gabriela Dogaru1, Andreea-Sabina Scripcă ${ }^{2}$, Adina-Eliza Croitoru ${ }^{2}$, Marieta Motricală $\breve{3}^{3}$, Adriana \\ Bulboacă ${ }^{1}$, Ioana Stănescu ${ }^{1}$ \\ 1. "Iuliu Hațieganu" University of Medicine and Pharmacy Cluj-Napoca, Clinical Rehabilitation Hospital
}

2. Faculty of Geography, "Babeș-Bolyai” University, Cluj-Napoca

3. S.C. Tușnad S.A.

p: $76-81$

Coresponding author: Gabriela Dogaru

E-mail address: dogarugabrielaumfci@yahoo.ro

\begin{abstract}
Băile Tuşnad balneoclimatic resort is situated in the south of the Ciuc depression, at an altitude of 625-655 m. The natural therapeutic factors used at the S.C. Tuşnad S.A. treatment facility are hypotonic carbonated mineral waters containing sodium chloride, calcium, magnesium, iron, carbon dioxide, with a total mineral content of 0.68-17.86 g/L, which are traditionally used for their vasodilator effects in the prevention, therapy and rehabilitation of cardiovascular patients, as well as mofettes and a relaxing sedative bioclimate. Although treatments have been performed for at least 5 decades in this resort, so far there are no data regarding the time effects of these medical rehabilitation treatments and procedures carried out in Tușnad resort. Therefore, the aim of this study was to investigate the patients' perception of their quality and efficacy, especially since very many patients come here once or even twice a year for treatment. Thus, in the period October-December 2017, a study was conducted at S.C. Tuşnad S.A. which included 394 subjects, patients of the treatment facility. These were aged between 39 and 87 years. The geographical distribution of the patients spanned the entire territory of Romania, with the predominance of Harghita, Covasna and Mureș counties, and in terms of the living environment, $43.91 \%$ of patients lived in rural areas and 56.09\% lived in urban areas. Before treatment, the patients were evaluated by a questionnaire specially designed to investigate various clinical data regarding the efficacy of treatments in the resort. The answers of patients who visited the resort regularly (once and/or twice a year) showed the fact that the most important clinical symptom that improved was pain (61.29\%), followed by quality of life (23.66\%), but there was also an improvement in the quality of gait and an increase in the walking distance (10.22\%). The time period required to perceive the effect of treatment was two weeks for the majority of the analyzed persons (47.31\%). Over $60 \%$ of the questioned patients indicated a period of about 6 months after the completion of treatment during which they felt better and the intensity of pain was tolerable.
\end{abstract}

Key words: balneotherapeutic effects, duration, pain intensity, carbonated mineral waters

\section{Introduction}

The natural therapeutic factors of Tuşnad resort include climatic factors, used in climatotherapy, as the resort benefits particularly during summer and transition seasons from a relaxing sedative climate, which stimulates the body functions. Surveys regarding air ionization indicate a concentration of 880 ions $/ \mathrm{cm}^{3}$ and a unipolarity coefficient of 1.18 [1]. Another important natural factor used at the S.C. Tuşnad S.A. treatment facility is represented by hypotonic carbonated mineral waters containing sodium chloride, calcium, magnesium, iron, carbon dioxide, with a total mineral content of $0.68-17.86$ $\mathrm{g} / \mathrm{L}$, which are traditionally used for their vasodilator effects in the prevention, therapy and rehabilitation of cardiovascular patients. For internal treatment, carbonated mineral water from springs 2,3 and 4 is used. External treatment is based on mineral water from springs 7 and 8, which is captured and driven through pipes to the treatment facility, where it is utilized in two large pools and in bathtubs for individual bathing. Natural gas in the form of natural mofettes, which are carbon dioxide emissions, is used for therapy and rehabilitation in specially designed rooms, and its effects occur through the action of carbon dioxide absorbed by the skin, to which the effects of inhaled carbon dioxide are added [2, 3].

The main therapeutic indications in the treatment facility are cardiovascular diseases, arterial hypertension, peripheral arterial disease through atherosclerosis, asthenic neurosis, associated digestive, renal diseases, occupational diseases and degenerative articular disorders [2,3].

Carbon dioxide baths have an old history and are considered effective in the treatment of peripheral vascular diseases [4]. While there are many literature studies on the efficacy of carbonated mineral waters in cardiovascular diseases, the number of randomized controlled trials is reduced. According to a study, in a complete bath, 10 up to more than $80 \mathrm{ml} / \mathrm{min} / \mathrm{m}^{2} \mathrm{CO} 2$ are absorbed through the skin, with a mean of 30 $\mathrm{ml} / \mathrm{min} / \mathrm{m}^{2}$ CO2 (equivalent to 1.8-4.5 L/h), depending on concentration, the measurement method and water temperature. CO2 is mostly absorbed at temperatures of 32-34 degrees Celsius, in hypothermal baths. This corresponds to a proportion of $10-12 \%$ of the amount of CO2 to which the body is exposed during this period. Consequently, CO2 is absorbed by the body 100 times more than water [5]. 
A wide variety of indications of carbonated mineral water baths is mentioned in the literature, while there is clear evidence from controlled trials only for a small number of these, mainly for chronic circulatory disorders based on atherosclerotic diseases such as peripheral arterial occlusive disease, trophic ulcerations, microangiopathies of various origins and mild arterial hypertension [6]. Experimental analyses, performed in human subjects and laboratory animals, have shown that the increase of skin blood flow in carbonated water baths results from the action of percutaneous $\mathrm{CO} 2$, inducing cutaneous vasodilation at relatively low water temperatures [7].

In animal experiments, CO2 baths have an effect on experimentally induced inflammation. It was shown that carbonated water frequently aggravates inflammation, but that addition of $\mathrm{NaCl}$ in a 3\% concentration ensures an anti-inflammatory effect. This suggests that the general picture of chemical components in a therapeutic spring should always be kept in mind.

According to existing studies, the desired long-term effects of $\mathrm{CO} 2$ baths can only be obtained by serial applications which determine the final efficacy of CO2 baths. These long-term effects are not only the sum of individual effects, but they are rather induced by fundamental changes in the autonomic nervous system regarding stimulation, response and adaptation therapy $[8,9]$.

A study conducted in a group of 20,000 patients (80\% with stage II intermittent claudication) treated for 3 weeks with thermal gas (99.5\% CO2), a therapy provided by means of thermal water or dry gas (general or local immersion and local subcutaneous injections with gas) in a treatment center in Royat (Auvergne), demonstrated the local vasodilator effects of CO2, as well as an increase in the walking distance and an improvement of the ankle blood pressure after treatment compared to a control group [10].

A recent study carried out in Italy investigated the specific effects of successive $\mathrm{CO} 2$ baths on the release of plasma free radicals, being the first study on oxidative status markers and balneotherapy with carbonated mineral water. Based on the data of this study, there are reasons to believe that an increase in the free radical neutralizing activity is beneficial in arterial occlusive diseases and that this activity can reduce the systemic and local inflammatory response found after ischemia-reperfusion lesions [11].
The neutralizing agent might be the carbonated mineral water baths [12]. This study demonstrated a reduction of oxidative stress after 2 weeks of balneotherapy with carbonated mineral water in patients with chronic arterial occlusive disease. The increase of cutaneous blood flow that persists throughout the duration of carbonated mineral water baths is interpreted as an increase of microcirculation. However, the inhibitory effect on free oxygen radicals can partly explain the efficacy of these baths with carbonated mineral water [13,14].

According to specialized studies, CO2 baths might represent an effective therapeutic means in the rehabilitation of coronary heart disease, myocardial infarction and stroke, as well as in the treatment of chronic venous insufficiency, some inflammatory diseases and functional disorders $[15,16]$.

Studies conducted in Băile Tuşnad on the efficacy of treatments in post-stroke $[17,18,19,20]$ and chronic arterial occlusive disease patients [21] evidenced an improvement of pain, balance and an increase in the walking distance. Also, preliminary results are available regarding a possible hepatoprotective effect of mixed carbonated mineral water from spring 3 in experimentally induced alcoholic liver injury [22,23]. However, according to these results, there are currently no data referring to the time effects of these medical rehabilitation treatments indicated for patients, which include specific natural factors from Băile Tuşnad, i.e. carbonated mineral waters and mofettes. The aim of this study was to investigate the patients' perception of the quality and time efficacy of these balneotherapeutic treatments, especially since very many patients come here once or even twice a year for treatment.

\section{Material and method}

In the period October-December 2017, 394 patients from the S.C. Tuşnad S.A. treatment facility in Băile Tusnad balneoclimatic resort were studied. Of these, 232 were women (58.88\%) and 162 (41.12\%) were men, aged between 39 and 87 years, the patients' mean age being 67 years.

The geographical distribution of the patients by residence county spanned the entire territory of Romania, but more than half of the patients came from Harghita, Covasna and Mureș counties $(28.17 \%$, $12.44 \%$, and $9.90 \%$, respectively). Depending on the environment of origin, $43.91 \%$ of patients lived in rural areas and 56.09\% lived in urban areas. 
This was a retrospective longitudinal study. Before their inclusion in the study, the patients' informed consent was obtained.

All patients included in the study were diagnosed with degenerative rheumatism: coxarthrosis, gonarthrosis, cervico-dorso-lumbar spondylarthrosis, omarthrosis, cervical and lumbar discopathy, status post hip and/or knee arthroscopy. Most of the patients reported more intense pain in the lumbar spine (21.74\%), knee (20.72\%), shoulder (17.65\%), hip (15.60\%) and cervical spine (12.53\%). In a smaller proportion, pain located in other joints was indicated (hand and leg joints - 5.37\%, multiple locations in the spine $-2.56 \%$, elbow $-2.05 \%$, ankle $-1.28 \%$, thoracic spine $-0.26 \%$ and plantar area $-0.26 \%$ ). The patients had associated hypertension, ischemic heart disease, diabetes mellitus, a history of stroke or myocardial infarction, chronic arterial occlusive disease, hepatic steatosis and chronic gastritis. Each patient attended an individualized medical rehabilitation treatment for 14 days, which consisted of carbonated mineral water baths for 20 minutes, mofettes with a progressive duration of 5 to 20 minutes, electrotherapy for analgesic purposes, aerotherapy, massage, kinesiotherapy, crenotherapy.

Before treatment, the patients were evaluated by a questionnaire specially designed to investigate various clinical data regarding the efficacy of treatments in Băile Tușnad balneoclimatic resort. The questions specifically designed by the authors for this analysis were:

i. How often did/do you visit Băile Tuşnad balneoclimatic resort? (with the answer variants: a) this is the first time that I visit the resort; b) I visit it once a year; c) I visit it twice a year; d) I visit it every two years; e) another answer);

ii. What are the clinical symptoms that most obviously improved following the treatments performed in the resort? (with the answer variants: a) pain; b) walking; c) quality of life; d) functional independence; e) other; f) there was no improvement; g) I do not know/I do not answer);

iii. How soon after the completion of procedures did you observe a clinical improvement? (with the answer variants: a) after a week; b) after two weeks; c) after three weeks; d) after a month; e) after more than a month; f) I observed no improvement; g) I do not know/I do not answer);

iv. How long did the effect of treatments in Băile Tușnad balneoclimatic resort last? (with the answer variants: a) for up to a month; b) for up to two months; c) for up to six months; d) for more than six months; f) not at all; g) I do not know/I do not answer).

Regarding the way of approaching the patients, the questions were asked individually, on the day of arrival of each patient at the resort, immediately after the medical examination.

In order to systematize the patients' answers, frequency for each item was calculated, but depending on the question, only valid answers were included in the subsequent analysis. We considered it appropriate to perform an analysis of all the answers of patients coming for treatment (biannually, annually, every two years, or having come for treatment in the past, without a certain cyclicity of balneotherapeutic procedures and treatments in Băile Tuşnad resort), as well as an analysis summarizing only the answers of patients regularly visiting Băile Tușnad balneoclimatic resort (biannually and annually). Except the first question (i.), for the other questions (ii., iii., iv.) we excluded from the analysis the answers of patients who were for the first time in the resort at the time of the study. So, for the first question (i.), frequencies were calculated in relation to 394 subjects. The answers to questions ii., iii., iv. were processed by calculating frequencies based on two samples: patients having attended treatment in the resort before (233 subjects), and patients attending treatment biannually and annually (186 subjects). We consider that the analysis based on the second group has a higher accuracy, the patients' answers being more precise due to a much more extensive experience compared to that of the other patients. Also, in this situation, the patients' observations can be considered "systematic", which eliminates the mere coincidence of pain improvement in the period immediately following the treatment.

\section{Results and discussions}

By analyzing the frequency of patients' treatment attendance in Băile Tuşnad balneoclimatic resort, the results show the fact that the majority of the patients regularly visited the resort and the treatment facility, because of all 394 interviewed subjects, 46.45\% attended treatment once a year and $0.76 \%$ came for treatment twice a year. $4.57 \%$ of the subjects came for treatment every two years and $40.86 \%$ of the patients attended treatment for the first time (Fig. 1). 


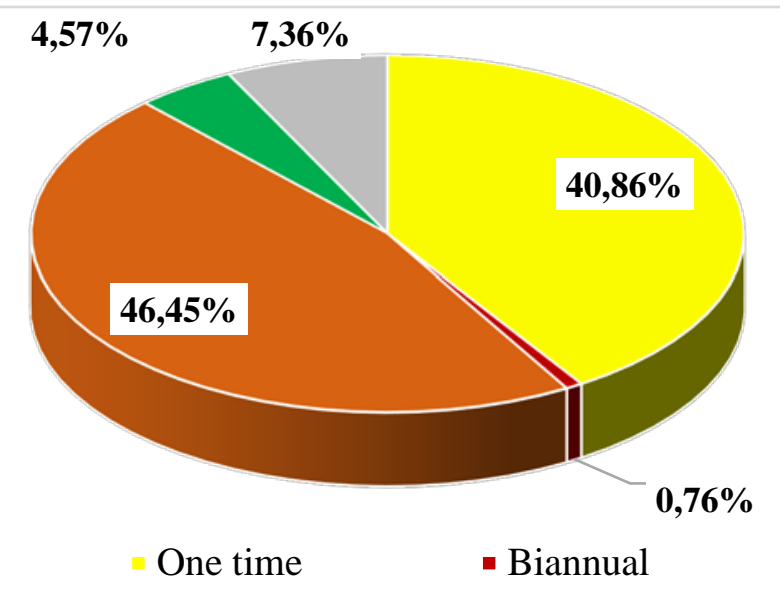

Fig. 1. Frequency of treatment in Tuşnad balneoclimatic resort

The "another answer" variant was chosen by 27 patients who had attended treatments in Băile Tuşnad in the past. Of these 27 persons, 20 had attended treatment once, and 7 patients had attended treatment at least two times before.

A retrospective analysis of the clinical symptoms that most obviously improved following treatment showed that the overwhelming majority of the patients (55-61\%) visiting the resort both regularly and occasionally reported an improvement of pain. Secondarily, the patients observed an improvement of quality of life in a proportion of $22-24 \%$, also regardless of the frequency of their visits to the resort. An improvement in the quality of gait and/or an increase of functional independence was reported by a considerably smaller number of patients (9-10\% and $5 \%$, respectively) compared to the previously mentioned symptoms (Fig. 2).

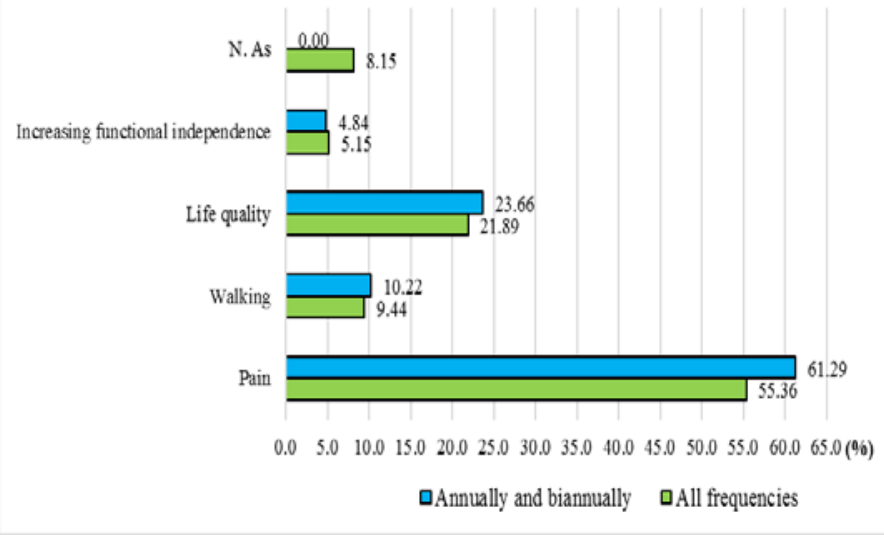

Fig. 2. Improved clinical symptoms
By analyzing the time period after which the patients observed a clinical improvement, it was found that the majority of the patients reported an improvement of their health status or quality of life in general, after two weeks (43-47\%) or even after one week (34-37\%) from completion of procedures. The fewest subjects reported having felt better after three weeks (about $12 \%$ for both analyses) or even after one month from completion of procedures (3-4\%) (Fig. $3)$.

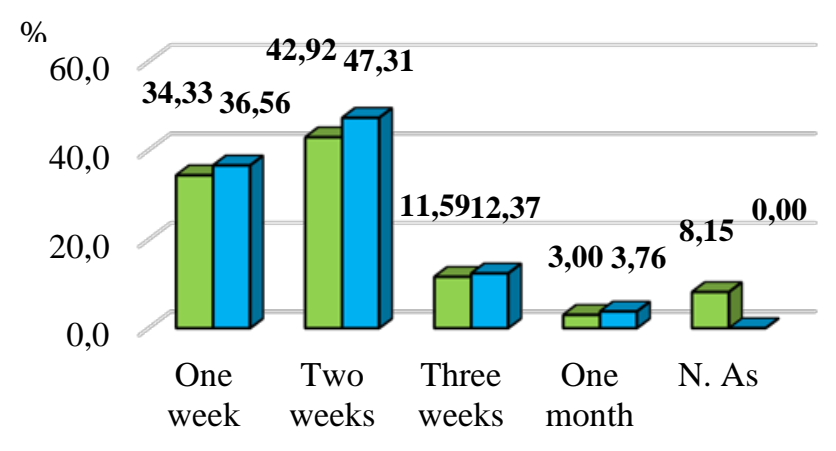

$\square$ All frequencies

Fig. 3 The time period from completion of procedures after which the patients observed a clinical improvement

Regarding the duration of the treatment effect, all patients reported a duration longer than one month, with the highest frequency of those who felt the effect over a duration of 2-6 months after completion of treatment (54-62\%). Secondarily, about one third of the patients (33\%) reported that the effect of treatments lasted for more than six months (Fig. 4).

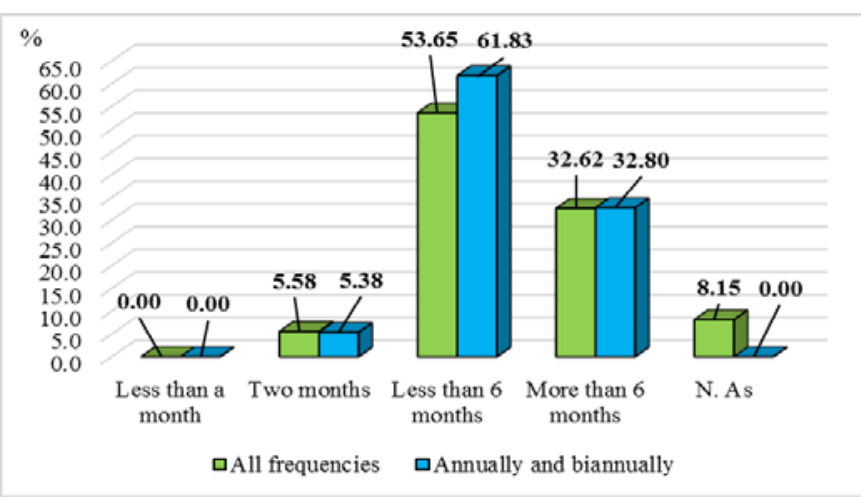

Fig. 4. Duration of the effect of treatment and medical procedures performed in the resort

An analysis of the duration of the treatment effect depending on the patients' age evidenced the fact that for the majority of the patients, regardless of age, the effect of treatment did not exceed six months. 
A special situation was found in the $\geq 81$ years age group, where for about one quarter of the patients, the effect of the treatments performed was reduced (two months) (Fig. 5). This result might highlight the fact that elderly patients sometimes have more advanced arthrosic changes and multiple associated diseases.

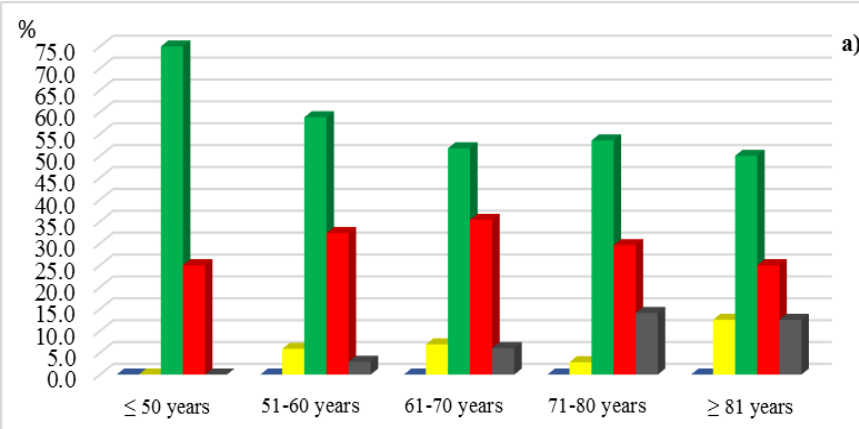

Less than a month $\square$ Two months $\square$ Less than 6 months $\square$ More than 6 months $\square$ N. As

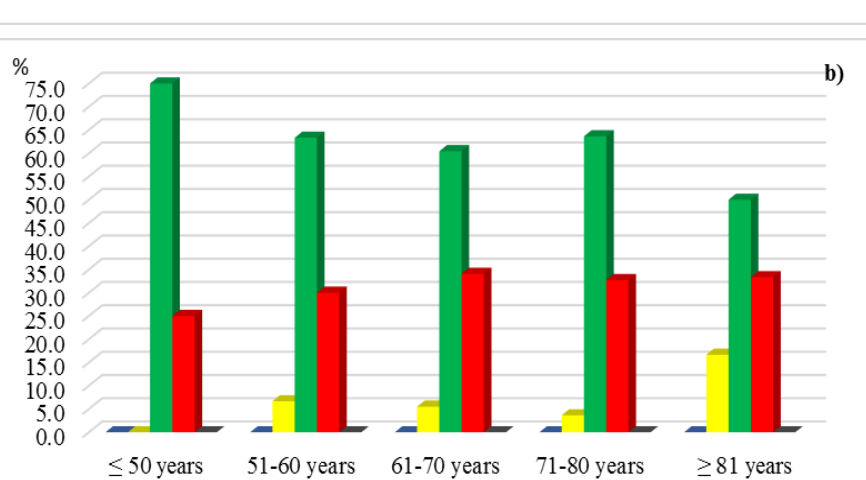

$\square$ Less than a month $\square$ Two months $\square$ Less than 6 months $\square$ More than 6 months $\square$ N. As

Fig. 5. Duration of the positive effect of treatment by age groups: $\mathrm{a}$ - all patients having come for treatment in the past; $\mathrm{b}$ - patients coming for treatment regularly (once or twice a year)

It should be noted that the highest frequency of the maximum duration of positive effects (more than 6 months after completion of treatment) was recorded in the 61-70 years age group. For the other age groups, frequency decreased by up to $10 \%$ in the case of persons who occasionally visited the resort. In the case of persons who regularly attended treatment (once or twice a year), the high frequency of the longterm effect (more than 6 months) was maintained in the more advanced age groups (71-80 years and over 80 years), the difference compared to the frequency of the $61-70$ years age group being of less than $1 \%$. This could be explained, at least partially, by the fact that in the case of a regular attendance, the positive effects persisted for a longer time period, even in the case of a general weakening of the body and the development of other disorders or the aggravation of existing ones with aging, which might be partially compensated by the treatment and procedures performed in the resort.

In this context, additional investigations should be carried out to test this hypothesis. In the case of its confirmation, public prevention policies should take into consideration the possibility of subsidizing two rest and treatment tickets per year, so that the most vulnerable persons can benefit from two courses of treatment per year, for the maximization of the beneficial effect of balneotherapy.

\section{Conclusions}

The main objective of this study was to investigate the quality and duration of the effect of treatments and medical procedures in Băile Tuşnad balneoclimatic resort: carbonated mineral water baths, mofettes, crenotherapy, aerotherapy, along with kinesiotherapy, massotherapy and electrotherapy.

We consider it appropriate to also mention the principal limitations of this study: not all patients had a known degree of arthrosis because of the lack of medical documents indicating the degree of joint impairment; the relatively small number of analyzed subjects; the absence of data quantifying the patients' lifestyle (physical activity, diet, standard of living); the lack of objective measurements.

It is important to highlight the fact that a large part of the interviewed subjects (47.21\%) were long-time patients of the resort, attending treatment once and twice a year. This evidences the quality and efficacy of the treatments performed in this resort and the patients' choice to maintain their well-being and/or improve their health status.

The results of this study are in accordance with those of international studies [8,9], which show the fact that the long-lasting (medium and long-term) beneficial effects of $\mathrm{CO} 2$ baths and balneotherapeutic treatments can only be obtained by serial applications that ensure their final efficacy. These medium and long-term effects are not only the sum of individual effects, but are rather induced by fundamental changes in the autonomic nervous system regarding stimulation, response and adaptation therapy, according to the literature data. Further studies are required.

Strictly referring to the answers of patients who regularly visited the resort, i.e. annually and biannually, every six months, the main positive effects of treatment were an improvement of pain (in 
more than $60 \%$ of the patients), and also, an improvement in the quality of gait and an increase in the walking distance. However, it should be noted that about one quarter of the interviewed subjects reported an increase in quality of life, in general.

The first beneficial effects of treatment were felt by most of the patients about two weeks after initiation of medical procedures (47.31\%), and the duration of the maximum positive effect ranged between 2 and 6 months in more than $60 \%$ of the patients, regardless of the analyzed age groups.

\section{References}

1. Elena Teodoreanu, Ovidiu Gaceu. Turism balneoclimatic în Romania. Editura Universităţii din Oradea, 2013

2. Munteanu Constantin. Ape minerale terapeutice. Editura Balneara, Bucuresti, 2013

3. Dogaru Gabriela, Radulescu Alexandru. Therapeutic effects of carbonated mineral waters in cardiovascular rehabilitation. Balneo Research Journal 2015;6(1):3943

4. Radawski D, Dabney JM, Daugherty RM, Jr., Haddy FJ, Scott JB. Local effects of CO2 on vascular resistances and weight of the dog forelimb. Am J Physiol 1972;222:439-443

5. Pratzel H. Aufnahme, Abgabe und Stoffwechsel von CO2 beim Kohlensäurebad. Z phys Med Blan Med Klim 1984;13:25-32

6. Resch KL, Just U. Possibilities and limits of CO2 balneotherapy. Wien Med Wochenschr 1994;144:45506

7. Hashimoto M, Yamamoto N. Decrease in heart rates by artificial CO2 hot spring bathing is inhibited by beta1adrenoceptor blockade in anesthetized rats. J Appl Physiol 2004;96:226- 232

8. Arnelung W, Hildebrandt G. Balneologie und Medizische Klimatologie, Bd 2, Balneologie, Springer, Wien, Heidelberg, New York, Tokyo, 1985

9. Hildebrandt G, Steinke L. Zur Frage der Kreislaufumstellung während CO2/Badekur. Arch Phys Ther 1962;14: 321-326

10.Fabry R, Dubost JJ, Schmidt J, Body J, Schaff G, Baguet JC. Thermal treatment in arterial disease: an expensive placebo or an effective therapy? Therapie 1995; 50(2):113- 22

11.Lau CS, Scott N, Shaw JW, Belch JJ. Increased activity of oxygen free radicals during reperfusion in patients with peripheral arterial disease undergoing percutaneous peripheral artery balloon angioplasty. Int Angiol 1991;10:244-246

12. Hashimoto M, Yamamoto N. Decrease in heart rates by artificial CO2 hot spring bathing is inhibited by beta1adrenoceptor blockade in anesthetized rats. J Appl Physiol 2004;96:226- 232
13.Resch KL, Just U. Possibilities and limits of CO2 balneotherapy. Wien Med Wochenschr 1994;144:4550

14.Hartmann B, Drews B, Bassenge E. CO2-induced acral blood flow and the oxygen partial pressure in arterial occlusive disease. Dtsch Med Wochenschr 1991;116:1617-1621

15.Irie H, Tatsumi T, Takamiya M, Zen K, Takahashi $\mathrm{T}$, Azuma A, Tateishi K, Nomura T, Hayashi H, Nakajima N, Okigaki M, Matsubara H. Carbon dioxide-rich water bathing enhances collateral blood flow in ischemic hindlimb via mobilization of endothelial progenitor cells and activation of NO-cGMP system. Circulation 2005;111:1523-1529

16. Toriyama T, Kumada Y, Matsubara T, Murata A, Ogino A, Hayashi H, Nakashima H, Takahashi H, Matsuo H, Kawahara H. Effect of artificial carbon dioxide foot bathing on critical limb ischemia (Fontaine IV) in peripheral arterial disease patients. Int Angiol 2002;21:367-373

17.Dogaru Gabriela, Ispas Alexandra, Stanescu Ioana, Motricala Marieta, Ákos Molnar. A clinical study on the efficacy of natural therapeutic factors in Băile Tuşnad for the rehabilitation of post-stroke patients. Balneo Research Journal 2017; 8 (1):5-10

18.Gabriela Dogaru, Alexandra Ispas, Adriana Bulboacă, Marieta Motricală, Ioana Stănescu. Influence of balnear therapy at Băile Tușnad on quality of life of post-stroke patients. Balneo Research Journal 2017;8(4):201-205.

19.Frîngu Fringu, Guşetu Gabriel, Iosip Adriana, Gurzău Diana, Dogaru Gabriela, Zdrenghea Dumitru, Pop Dana. The predictors of exercise capacity impairment in diabetic patients. Balneo Research Journal 2017;8(2): 26-32.

20.Gabriela Dogaru, Motricală Marieta, Adriana Bulboacă, Lorena Ciumărnean, Ioana Stănescu. The effect of carbonated mineral water and mofette treatment in Baile Tusnad after ischemic stroke - a case report. Balneo Research Journal 2018; 9 (1): 11-14

21.Dogaru Gabriela, Stanescu Ioana, Pop Daniela, Motricală Marieta, Ákos Molnar. Effects of carbonated mineral water treatment in Băile Tuşnad on chronic arterial occlusive disease - a case report. Balneo Research Journal 2017; 8 (3): 121-124.

22.Gabriela Dogaru, Marieta Motricală, Molnár Ákos, Vasile Rus. Effects of mineral water from spring 3 in Băile Tuşnad on experimentally induced alcoholic liver disease. Balneo Research Journal 2017;8(3):125-128.

23.Gabriela Dogaru, Marieta Motricală, Molnár Ákos, Vasile Rus. An experimental study regarding the biological effects of mineral water from Spring 3 in Baile Tusnad on some organs after ethyl alcohol administration. Balneo Research Journal 2016;7(1):2328. 